\title{
miR-196b regulates gastric cancer cell proliferation and invasion via PI3K/AKT/mTOR signaling pathway
}

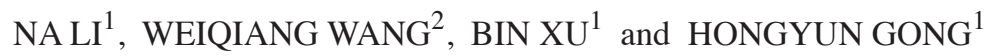 \\ ${ }^{1}$ Department of Oncology, Renmin Hospital of Wuhan University, Wuhan, Hubei 430060; \\ ${ }^{2}$ Department of Gastroenterology, 281st Hospital of the PLA, Qinhuangdao, Hebei 066100, P.R. China
}

Received December 15, 2014; Accepted December 7, 2015

DOI: $10.3892 / \mathrm{ol} .2016 .4141$

\begin{abstract}
R-196b plays a significant role in the regulation of tumor pathogenesis and progression by promoting tumor cell proliferation, invasion and metastasis. In order to explore the effects of miR-196b on the proliferation and invasion ability of gastric cancer cells and the involved mechanisms, in the present study the lentivirus expression vector miR-196b was constructed and transfected into the human gastric cancer cell line MKN28. The cell proliferation and invasion ability were observed and the expression of $\mathrm{PI} 3 \mathrm{~K} / \mathrm{AKT} / \mathrm{mTOR}$ protein and mRNA were analyzed following upregulation of the expression of miR-196b. 3-(4,5-dimethylthiazol-2-yl)-2,5-diphenyltetrazolium bromide (MTT) results revealed that the proliferation of MKN28 cells was notably increased following upregulation of the expression of miR-196b $(\mathrm{P}<0.01)$. Flow cytometry analysis demonstrated that miR-196b decreased the ratios of cells in the $\mathrm{GO} / \mathrm{G} 1$ stage but increased the ratios in $\mathrm{S}$ and $\mathrm{G} 2$ stage $(\mathrm{P}<0.05)$. Furthermore, the cell clone formation and trans-membrane rates were increased following upregulation of the expression of miR-196b $(\mathrm{P}<0.01)$. The nude mouse tumor growth test revealed that tumor growth was more rapid following upregulation of the expression of miR-196b. The expression of PI3K/AKT/mTOR protein and mRNA were increased following upregulation of the expression of miR-196b. We concluded that upregulation of miR-196b promotes the proliferation and invasion ability of gastric cancer cells by regulating the PI3K/AKT/mTOR pathway.
\end{abstract}

\section{Introduction}

Gastric cancer is a common type of tumor with high incidence and mortality rates which poses a significant threat to human life. As the mechanism of gastric carcinogenesis is still

Correspondence to: $\mathrm{Dr} \mathrm{Na} \mathrm{Li}$, Department of Oncology, Renmin Hospital of Wuhan University, 99 Zhangzhidong, Wuhan, Hubei 430060, P.R. China

E-mail: linawuhan2013@163.com

Key words: miR-196b, gastric cancer, proliferation, invasion, PI3K, AKT, mTOR unknown, the study of gastric cancer initiation and progression and the search for new therapeutic targets are currently hot research topics. microRNA (miR) is a newly identified single-stranded non-coded RNA containing 17-19 nucleotides that is a significant regulator of gastric cancer initiation and progression. A series of studies has reported that miR plays an essential regulatory role in the proliferation, invasion and metastasis of gastric cancer cells and in cell apoptosis (1-8). miR-196 was demonstrated to be associated with involution of normal tissues, rib (9), tail (10) and bone marrow (11), as well as regulation of cancers of the rectum $(12,13)$ and liver (14), and appears to be a potential target for cancer therapy (15). The PI3K/AKT/mTOR signaling pathway is known to be essential to cell apoptosis. To determine the effect of miR-196b in controlling apoptosis in gastric cancer cells, as well as the underlying mechanism, here we examined the correlation between miR-196b expression and apoptosis of MKN28 gastric cancer cells and assessed its role in controlling the PI3K/AKT signaling pathway.

\section{Materials and methods}

Lentivirus-based miR-196b vector production and its delivery to gastric cancer MKN28 cells. The following study was approved by the Ethics Committee of Wuhan University (Wuhan, China). Primers specific to human miR-196b (gene ID 442920) were designed as follows: 5'-CGGTTAACCCCTTCCTTGACGCATTTG-'3 (sense) and 5'-CGACTCGAGAACCTAACCCTACCTGCTGTGA-3' (anti-sense). The primers were synchronized by Takara Biotechnology Co., Ltd. (Dalian, China) by introducing $H p a \mathrm{I}$ and XhoI restriction enzyme sites at the terminals. The normal male peripheral blood genomic DNA template was used to amplify specific fragments by polymerase chain reaction (PCR). Then the PCR product and pLL-3.7 plasmid (Takara Biotechnology Co., Ltd.) were digested with HpaI and $\mathrm{XhoI}$ and ligated overnight using T4 ligase at $16^{\circ} \mathrm{C}$. The ligated product was transferred to E.coli STBL-3 competent cells (Takara Biotechnology Co., Ltd.) and selected for positive clones by plating on an ampicillin+LB plate. pLL-miR-196 plasmid was purified from the positive clones. Using Lipofectamine ${ }^{\circledR} 2000$ transfection reagent (Invitrogen; Thermo Fisher Scientific, Inc., Waltham, MA, USA), $10 \mathrm{mg}$ pLL-miR-196b and $5 \mathrm{mg}$ pCMV-VSV-G were delivered 
to HEK293FT cells (Cell Bank of the Chinese Academy of Science, Beijing, China). Prior to transfection, the cells were seeded on a six-well plate at a density of $2 \times 10^{6}$ cells per well and co-cultured with modified RPMI-1640 medium containing $2 \mathrm{ml} \mathrm{10 \%} \mathrm{fetal} \mathrm{bovine} \mathrm{serum} \mathrm{(FBS;} \mathrm{HyClone;}$ GE Healthcare Life Sciences, Logan, UT, USA) until confluence reached $70-90 \%$. Virus-containing cell culture fluid was collected at $48 \mathrm{~h}$ post-transfection, centrifugated at $3000 \mathrm{x}$ g for $15 \mathrm{~min}$ at $4^{\circ} \mathrm{C}$, filtered through a $0.45-\mu \mathrm{m}$ filter, and maintained at $-80^{\circ} \mathrm{C}$. MKN28 gastric cancer cells (Cell Bank of the Chinese Academy of Science) were incubated on a six-well plate at a density of $1 \times 10^{6}$ per well with modified RPMI-1640 medium supplemented with $2 \mathrm{ml} 10 \%$ FBS. After $24 \mathrm{~h}$, virus-containing supernatant was delivered to the cells to serve as the miR-196b group. For the control group, the same procedure was carried out, with the exception that the virus-containing supernatant was replaced with $100 \mu \mathrm{l}$ phosphate-buffered saline (PBS). The transduced cells demonstrated green fluorescence under the fluorescence microscope. The expression of miR-196b was measured using quantitative PCR (qPCR).

$q P C R$. When cells were in the exponential phase of growth, TRIzol reagent (Thermo Fisher Scientific, Inc.) was used to isolate total RNA. mRNA reverse transcription was generated using the RevertAid First Strand cDNA synthesis kit (Thermo Fisher Scientific, Inc.) following the instructions. The reaction system was as follows: $2 \mu 15 \mathrm{X}$ PrimeScript buffer, $2 \mu \mathrm{l}$ total RNA $(0.25 \mu \mathrm{g} / \mu \mathrm{l}), 1 \mu \mathrm{l}$ primers $(10 \mathrm{pM}), 0.5 \mu 1$ PrimerScript RT enzyme mix, and $6.5 \mu 1$ RNase-free $\mathrm{dH}_{2} \mathrm{O}$. The reaction parameters were $37^{\circ} \mathrm{C}$ for $15 \mathrm{~min}$, followed by $85^{\circ} \mathrm{C}$ for $5 \mathrm{sec}$ and $4^{\circ} \mathrm{C}$ for the hold. Quantitative analysis was performed using a Thunderbird SYBR ${ }^{\circledR}$ qPCR mix kit (Toyobo Co., Ltd., Osaka, Japan). The reaction system was as follows: $12.5 \mu \mathrm{l}$ 2X qPCR mix, $2.0 \mu \mathrm{l}$ of each $2.5 \mu \mathrm{M}$ primer, $2.0 \mu \mathrm{l}$ reverse transcription products, and $8.5 \mu \mathrm{l} \mathrm{ddH}_{2} \mathrm{O}$. The amplification parameters were 40 cycles of $95^{\circ} \mathrm{C}$ for $3 \mathrm{sec}, 95^{\circ} \mathrm{C}$ for $5 \mathrm{sec}$, $60^{\circ} \mathrm{C}$ for $30 \mathrm{sec}$, and $68^{\circ} \mathrm{C}$ for $45 \mathrm{sec}$. For the qPCR primers, see Table I.

Western blot analysis. Cells were lysed for total protein extraction using RIPA buffer (250 $\mu 1$, Beyotime Institute of Biotechnology, Shanghai, China) for $24 \mathrm{~h}$ after being incubated on a six-well plate. The expression of miR-196a, PI3K, AKT and mTOR was measured using a western blot kit (Biosdec, Wuhan, China). Rat anti-human miR-196a, PI3K, AKT and mTOR antibodies were purchased from Santa Cruz Biotechnology, Inc. (Santa Cruz, Dallas, TX, USA).

Successively, $50 \mu \mathrm{g}$ total protein was separated using sodium dodecyl sulphate-polyacrylamide gel electrophoresis, transferred to a $0.45 \mu \mathrm{m}$ polyvinylidene fluoride membrane and incubated overnight at $4^{\circ} \mathrm{C}$ with rat anti-human monoclonal antibody (1:3000 dilution). Following decoloration, horseradish peroxidase-conjugated goat anti-rabbit secondary antibody at a 1:3000 dilution was added for $30 \mathrm{~min}$ at room temperature and unbound antibody was washed away. Proteins were visualized by enhanced chemiluminescence detection reagents (Thermo Fisher Scientific, Inc.) and exposed to X-ray film after raffinate clearance. Exposure conditions and developing and fixing were based on the light intensity. Developed
Table I. Quantitative polymerase chain reaction primers.

\begin{tabular}{|c|c|}
\hline Gene & Primers $\left(5^{\prime} \rightarrow 3^{\prime}\right)$ \\
\hline miR-125a & $\begin{array}{l}\text { Sense: CGGTTAACCCCTTCCTTGACGCAT } \\
\text { TTG } \\
\text { Anti-sense: CGACTCGAGAACCTAACCCTA } \\
\text { CCTGCTGTGA }\end{array}$ \\
\hline PI3K & $\begin{array}{l}\text { Sense: GCCCAGGCTTACTACAGAG } \\
\text { Anti-sense: AAGTAGGGAGGCATCTCG }\end{array}$ \\
\hline AKT & $\begin{array}{l}\text { Sense: CTCATTCCAGACCCACGAC } \\
\text { Anti-sense: ACAGCCCCGAAGTCCGTTA }\end{array}$ \\
\hline mTOR & $\begin{array}{l}\text { Sense: ATGACGAGACCCAGGCTAA } \\
\text { Anti-sense: GCCAGTCCTCTACAATACGC }\end{array}$ \\
\hline$\beta$-actin & $\begin{array}{l}\text { Sense: ATCATGTTTGAGACCTTCAACA } \\
\text { Anti-sense: CATCTCTTGGTCGAAGTCCA }\end{array}$ \\
\hline U6 & $\begin{array}{l}\text { Sense: CTCGCTTCGGCAGCACA } \\
\text { Anti-sense: AACGCTTCACGAATTTGCGT }\end{array}$ \\
\hline
\end{tabular}

films were processed with BanScan software (Glyko Inc., Novato, CA, USA) to determine optical densities.

\section{3-(4,5-dimethylthiazol-2-yl)-2,5-diphenyltetrazolium}

bromide (MTT) method for analysis of cell proliferative activity. Cells were seeded on a 96-well plate at a density of 2000 cells per well. When the cells reached $80 \%$ confluence, the culture medium was removed before adding $20 \mu \mathrm{l}$ MTT reaction solution $(5 \mathrm{mg} / \mathrm{ml}$, Beyotime Institute of Biotechnology) to each well. Once the cells had been incubated in the dark for $4 \mathrm{~h}$ at $37^{\circ} \mathrm{C}$, the supernatant was removed and $150 \mu \mathrm{l}$ DMSO (Beyotime Institute of Biotechnology) was added to each well and agitated for $10 \mathrm{~min}$ at room temperature. Optical density was measured at $490 \mathrm{~nm}$ using the enzyme-linked immunosorbent assay.

Flow cytometry for analysis of cell cycle. Cells were seeded on a six-well plate at a density of $1 \times 10^{6}$ per well and allowed to incubate until cell adhesion using the conventional culture technique. The culture medium was removed, then cells were suspended, centrifuged and then fixed with precooled $75 \%$ ethanol overnight at $-20^{\circ} \mathrm{C}$. Cells were centrifuged to remove supernatant and washed twice with PBS. A total of $450 \mu \mathrm{l}$ PBS was added to each well to resuspend cells. Subsequently, $50 \mu 1$ propidium iodide $(0.5 \mathrm{mg} / \mathrm{ml}$, Beyotime Institute of Biotechnology) was added, agitated and the cells were maintained in a water bath at $37^{\circ} \mathrm{C}$ for $30 \mathrm{~min}$. Cells were again centrifuged to remove the supernatant and PBS was used to resuspend the cells. The cell cycle was determined by flow cytometer (BD-FACSCalibur, BD Biosciences, San Jose, CA, USA).

Soft agar colony formation assay. Soft agar (5\%) was added to the medium at a 1:9 ratio and mixed well before being placed on dishes and cooled at room temperature. Exponentially growing cell suspension containing $1 \times 10^{3}$ cells $/ \mathrm{ml}$ was prepared. Cell suspension $(1.5 \mathrm{ml})$ was then added to an 
$\mathbf{A}$

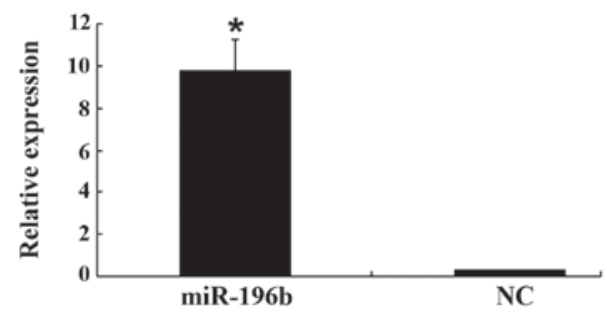

B

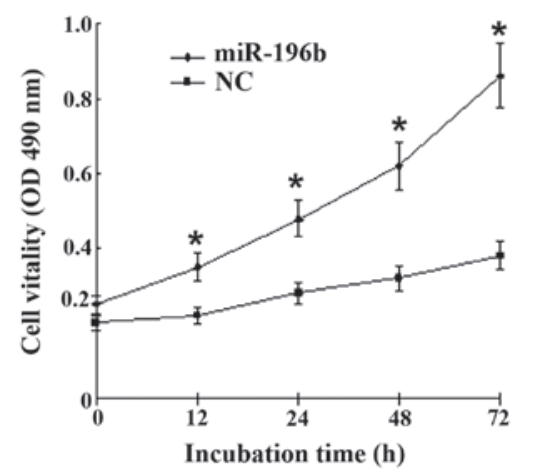

C

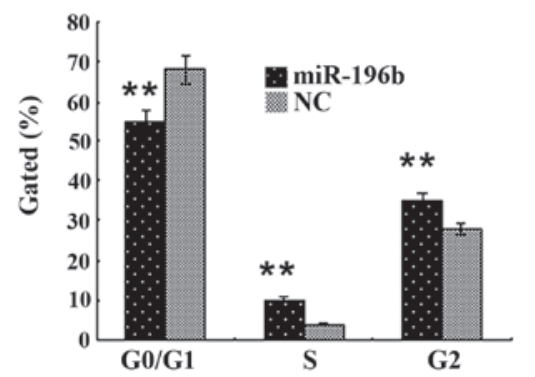

Figure 1. Upregulation of miR-196b induces gastric cancer cell proliferation and transition from GO/G1 phase to S phase. (A) miR-196b RNA was upregulated by miR-196b transfection; (B) Cell proliferation ability was enhanced by miR-196b transfection; (C) The number of cells in the G0/G1 phase was decreased and that in the $\mathrm{S}$ and G2 phase increased following miR-196b transfection. ${ }^{*} \mathrm{P}<0.01$ vs. control group, ${ }^{* *} \mathrm{P}<0.05$ vs. control group.

equal volume of $0.5 \%$ soft agar, agitated and incubated on a dish at $37^{\circ} \mathrm{C}$ under $5 \% \mathrm{CO}_{2}$ for 2 to 3 weeks. The formation of colonies was calculated using the formula: Colony formation rate $(\%)=($ number of colonies $/$ number of cells incubated) x 100 .

In vitro cell invasion assay. Cell invasion ability was tested using a Transwell chamber model (Chemicon; EMD Millipore, Billerica, MA, USA). Cell suspension was adjusted to a concentration of $1 \times 10^{5}$ cells $/ \mathrm{ml}$. Then, $50 \mu \mathrm{l}$ cell suspension was placed in the upper chamber. After $24 \mathrm{~h}$, cells that had migrated to the lower chamber were fixed with $10 \%$ formalin and stained with Giemsa to quantitate the number of transmigrated cells under an inverted microscope. The transmigration rate was the number of cells transmigrated over the total number of cells.

Tumorigenecity test in nude mice. Six 5-week-old BALB/c nude mice purchased from Wuhan University Center for Animal Experiments, China, were randomly assigned to the miR-196a group and control group, with three mice per group. In the miR-196a group, $1 \times 10^{5}$ miR-196a-transfected MKN28 cells were suspended in a serum-free RPMI-1640 medium $(0.1 \mathrm{ml})$, and administered by subcutaneous injection into the
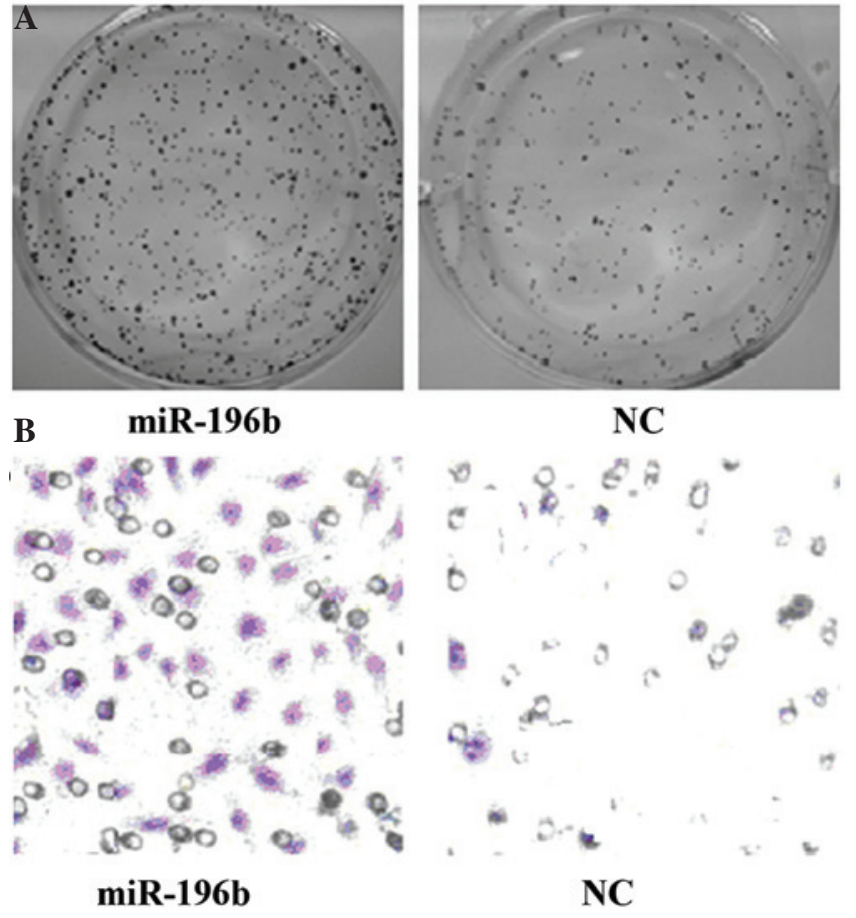

Figure 2. miR-196b activation induces gastric cancer cell cloning and invasion. (A) miR-196b induced a cloning efficiency of gastric cancer cells far higher than that observed in the control group; (B) miR-196b induced greater migration capacity in gastric cancer cells compared with the control group.

back of the nude mice. Three days later, another injection with the same number of cells at the same concentration was administered. In the control group, the mice underwent the same treatment as the miR-196a group with the exception that the MKN28 cells were not miR-196a-transfected. Animals were sacrificed 4 weeks after tumor formation and tumor weight was determined.

Statistical analysis. Data were expressed as the means \pm standard deviation and were processed with the paired t-test using SPSS 16.0 software (SPSS, Inc., Chicago, Illinois, USA). $\mathrm{P}<0.05$ was considered to indicate a statistically significant difference.

\section{Results}

Effect of miR-196b activation on gastric cancer cell proliferation. MKN28 cells exhibited green fluorescence when transfected with lentivirus-mediated miR-196b. In addition, the expression of miR-196b RNA was $\sim 20$-fold higher than that in the control group (Fig. 1A). The results of the MTT assay revealed that miR-196b activation enhanced the proliferative ability of MKN28 cells compared with that of the control group $(\mathrm{P}<0.01$; Fig. 1B). We assessed the effect of miR-196b on the cycle of gastric cancer cells by flow cytometry and observed that gastric cancer cells in the G0/G1 phase decreased, while those in the $\mathrm{S}$ and $\mathrm{G} 2$ phase of the cell cycle increased compared with the control group $(\mathrm{P}<0.05$; Fig. 1C).

Effect of miR-196b on gastric cancer cell cloning and invasion. Colony-forming cell assay revealed that the cell cloning efficiency increased to $(78 \pm 12) \%$ following miR-196b activation 
A

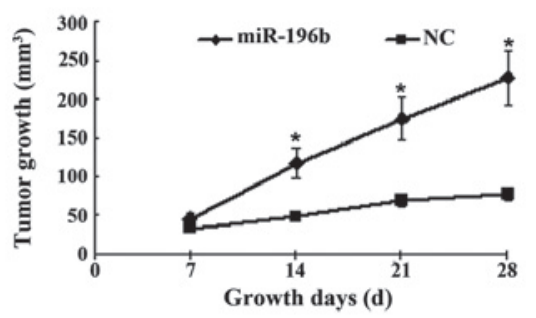

B

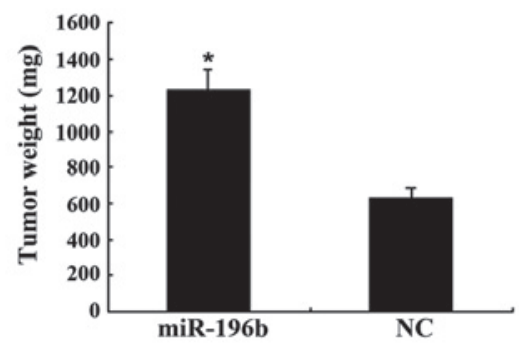

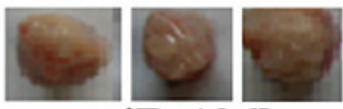

miR-196b

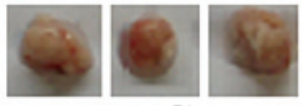

NC
Figure 3. In vitro tumor growth induced by miR-196b transfection (A) miR-196b induced growth of tumors; (B) Tumor weight was significantly higher than that in the control group 4 weeks after injection of miR-196b-transfected gastric cancer cells into nude mice. ${ }^{*} \mathrm{P}<0.01$ vs. control group.

A

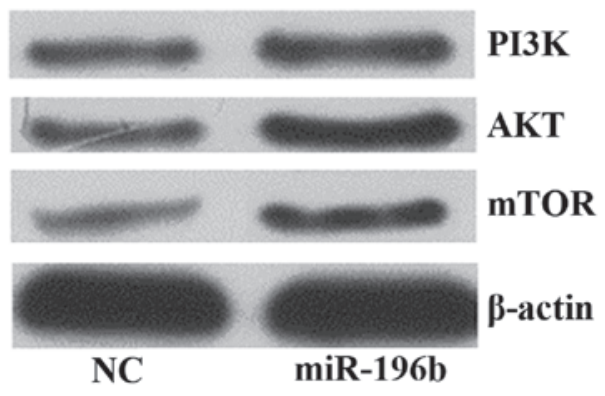

B

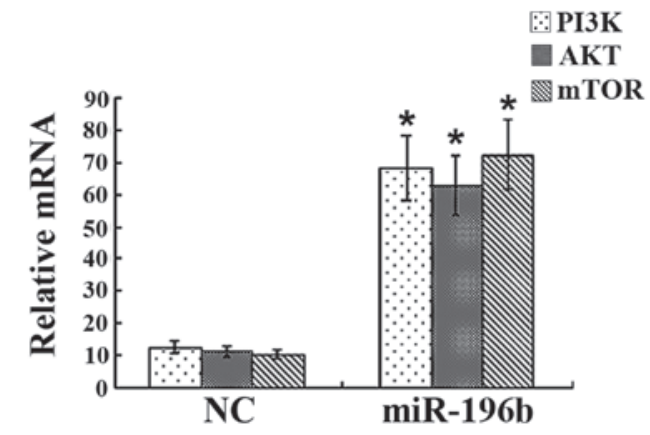

Figure 4. miR-196b regulates PI3K/AKT/mTOR expression in gastric cancer cells. (A) As demonstrated by western blot analysis, miR-196b induced a significantly higher expression of $\mathrm{PI} 3 \mathrm{~K} / \mathrm{AKT} / \mathrm{mTOR}$ protein $(\mathrm{P}<0.01)$; (B) As demonstrated by quantitative polymerase chain reaction analysis, miR-196b increased the expression of PI3K/AKT/mTOR mRNA to a level far higher than that in the control group $(\mathrm{P}<0.01)$. ${ }^{*} \mathrm{P}<0.01$ vs. control group.

compared with $(32 \pm 8) \%$ in the control group $(\mathrm{P}<0.01$; Fig. $2 \mathrm{~A})$. Transwell invasion assay revealed $(48 \pm 16) \%$ cell migration following miR-196b activation, which was far higher than the $(12 \pm 4) \%$ observed in the control group ( $\mathrm{P}<0.01$; Fig. $2 \mathrm{~B})$.
In vitro tumor growth induced by miR-196b transfection. The results of the tumorigenecity test revealed increased tumor growth following miR-196b transfection (Fig. 3A). Four weeks after injection of miR-196b-transfected gastric cancer cells into nude mice, the tumor weight was significantly higher than that of the control group $(\mathrm{P}<0.01$; Fig. $3 \mathrm{~B})$.

miR-196b regulates PI3K/AKT/mTOR expression. Western blot analysis revealed that the levels of PI3K/AKT/mTOR protein in gastric cancer cells were $0.38 \pm 0.06,0.46 \pm 0.08$ and $0.22 \pm 0.06$ in the miR-196b transfection group, which was far higher than the levels $0.18 \pm 0.03,0.16 \pm 0.04$ and $0.09 \pm 0.03$ observed in the negative control group ( $\mathrm{P}<0.01$; Fig. $4 \mathrm{~A})$. qPCR analysis demonstrated significant upregulation of $\mathrm{PI} 3 \mathrm{~K} / \mathrm{AKT} / \mathrm{mTOR}$ mRNA in gastric cancer cells following miR-196b transfection (Fig. 4B).

\section{Discussion}

A previous study reported that miR-196b played a significant role in human tissue evolution and tumor growth with particular emphasis on its role in the development and progression of tumors (15). This provided a promising targeted cancer therapy. miR-196b and miR-196a are each members of the miR-196 family, despite miR-196b exhibiting one basic group difference from miR-196a, they present similarities in terms of their molecular structure and function. miR-196b was demonstrated to have a positive effect on cancer proliferation, but a negative effect on tumor cell apoptosis and differentiation was implicated in the development and progression of leukemia and other cancer types. The expression of miR-196b was upregulated in short-term hematopoietic stem cells and downregulated in highly-differentiated hematopoietic stem cells (16). In addition, in mixed-lineage leukemia medullary cells, miR-196b demonstrated overexpression driven by the pathogenically abnormal MLL fusion protein (16) and became a target of HOX genes $(17,18)$.

The regulatory role of miR-196b in gastric cancer cells was investigated with lentivirus-mediated miR-196b transfection into gastric cancer cells. To verify the role of miR-196b in regulating gastric cancer cell proliferation, we conducted an MTT assay to measure the proliferative ability of gastric cancer cells following miR-196b activation, and observed that miR-196b enhanced cell proliferation (Fig. 1B). In addition, changes in gastric cancer cell cycle following miR-196b activation were detected using flow cytometry. As a result, cells progressing from the G0/G1 phase to the S phase were observed. Taken together, our results indicate a significant regulatory role of miR-196b in gastric cancer cell proliferation.

In our study, soft agar and Transwell assays were performed to validate the role of $\mathrm{miR}-196 \mathrm{~b}$ in regulating the proliferation and migration of gastric cancer cells. Soft agar colony formation assay is used to monitor tumor anchorage-independent growth and tumor malignancy; i.e., a stronger invasion ability of tumor cells is associated with a greater number of cell colonies (19-21). The Transwell chamber model, which imitates a cancer-associated microenvironment and extracellular matrix, is known to be a reliable method for assaying cell invasion ability (22). Our results identified a marked 
increase in the cloning efficiency and migration rate of gastric cancer cells following miR-196b activation, and implicated a metastasis-promoting role of miR-196b in gastric cancer cells (Fig. 2). In addition, to measure the role of miR-196b in cancer genesis and growth in vitro, we conducted tumorigenicity test in nude mice to assess cancer growth following miR-196b activation. It was observed that miR-196b induced tumor growth (Fig. 3).

The PI3K/AKT/mTOR signaling pathway is known to be significant in the genesis, invasion and migration of gastric cancer (23-26). Our study identified that PI3K/AKT/mTOR mRNA and protein were upregulated in gastric cancer cells following miR-196b activation, and implicated an active role of miR-196b in gastric cancer cells via the PI3K/AKT/mTOR pathway.

High expression of miR-196b contributes to gastric cancer proliferation and migration, and the mechanism is associated with the interference of the PI3K/AKT/mTOR signaling pathway. miR-196b may be a potential molecular target for gastric cancer therapy.

\section{References}

1. Wu R, Li F, Zhu J, Tang R, Qi Q, Zhou X, Li R, Wang W, Hua D and Chen W: A functional variant at mir-132-3p, mir-212-3p and mir-361-5p binding site in cd80 gene alters susceptibility to gastric cancer in a Chinese Han population. Med Oncol 31: 60, 2014.

2. Xu YJ and Fan Y: Mir-215/192 participates in gastric cancer progression. Clin Transl Oncol 17: 34-40, 2015.

3. Shen ZY, Zhang ZZ, Liu H, Zhao EH and Cao H: Mir-375 inhibits the proliferation of gastric cancer cells by repressing ERBB2 expression. Exp Ther Med 7: 1757-1761, 2014.

4. Li H, Xie S, Liu M, Chen Z, Liu X, Wang L, Li D and Zhou Y: The clinical significance of downregulation of mir-124-3p, mir-146a-5p, mir-155-5p and mir-335-5p in gastric cancer tumorigenesis. Int J Oncol 45: 197-208, 2014

5. Xia J, Guo X, Yan J and Deng K: The role of mir-148a in gastric cancer. J Cancer Res Clin Oncol 140: 1451-1456, 2014.

6. Zheng Y, Li S, Ding Y, Wang Q, Luo H, Shi Q, Hao Z, Xiao G and Tong S: The role of mir-18a in gastric cancer angiogenesis. Hepatogastroenterology 60: 1809-1813, 2013.

7. Duan Y, Hu L, Liu B, Yu B, Li J, Yan M, Yu Y, Li C, Su L, Zhu Z, et al: Tumor suppressor miR-24 restrains gastric cancer progression by downregulating regIV. Mol Cancer 13: 127, 2014.

8. He XJ, Ma YY, Yu S, Jiang XT, Lu YD, Tao L, Wang HP, Hu ZM and Tao HQ: Up-regulated miR-199a-5p in gastric cancer functions as an oncogene and targets klotho. BMC Cancer 14: $218,2014$.

9. Hornstein E, Mansfield JH, Yekta S, Hu JK, Harfe BD, McManus MT, Baskerville S, Bartel DP and Tabin CJ: The microRNA-miR-196 acts upstream of hoxb8 and shh in limb development. Nature 438: 671-674, 2005.

10. Sehm T, Sachse C, Frenzel C and Echeverri K: miR-196 is an essential early-stage regulator of tail regeneration, upstream of key spinal cord patterning events. Dev Biol 334: 468-480, 2009.
11. Kawasaki H and Taira K: MicroRNA-196 inhibits HOXB8 expression in myeloid differentiation of HL60 cells. Nucleic Acids Symp Ser (Oxf) 48: 211-212, 2004.

12. Brest P, Lapaquette P, Souidi M, Lebrigand K, Cesaro A, Vouret-Craviari V, Mari B, Barbry P, Mosnier JF, Hébuterne X, et al: A synonymous variant in IRGM alters a binding site for miR-196 and causes deregulation of IRGM-dependent xenophagy in crohn's disease. Nat Genet 43: 242-245, 2011.

13. Hezova R, Kovarikova A, Bienertova-Vasku J, Sachlova M, Redova M, Vasku A, Svoboda M, Radova L, Kiss I, Vyzula R and Slaby O: Evaluation of SNPs in miR-196-a2, miR-27a and miR-146a as risk factors of colorectal cancer. World J Gastroenterol 18: 2827-2831,2012.

14. Hou W, Tian Q, Zheng J and Bonkovsky HL: MicroRNA-196 represses Bach1 protein and hepatitis $C$ virus gene expression in human hepatoma cells expressing hepatitis $\mathrm{C}$ viral proteins. Hepatology 51: 1494-1504, 2010.

15. Chen C, Zhang Y, Zhang L, Weakley SM and Yao Q: MicroRNA-196: Critical roles and clinical applications in development and cancer. J Cell Mol Med 15: 14-23, 2011.

16. Popovic R, Riesbeck LE, Velu CS, Chaubey A,Zhang J, Achille NJ, Erfurth FE, Eaton K, Lu J, Grimes HL, et al: Regulation of mir-196b by MLL and its overexpression by MLL fusions contributes to immortalization. Blood 113: 3314-3322, 2009.

17. Schotte D, Lange-Turenhout EA, Stumpel DJ, Stam RW, Buijs-Gladdines JG, Meijerink JP, Pieters R and Den Boer ML: Expression of miR-196b is not exclusively MLL-driven but is especially linked to activation of HOXA genes in pediatric acute lymphoblastic leukemia. Haematologica 95: 1675-1682, 2010.

18. Li Z, Huang H, Chen P, He M, Li Y, Arnovitz S, Jiang X, He C, Hyjek E, Zhang J, et al: miR-196b directly targets both HOXA9/MEIS1 oncogenes and FAS tumour suppressor in MLL-rearranged leukaemia. Nat Commun 3: 688, 2012.

19. Abbud-Antaki RA, Marhefka JN,DeLuca AL andZuromskis MP: The cancer biochip system: a functional genomic assay for anchorage-independent three-dimensional breast cancer cell growth. Horm Cancer 3: 261-270, 2012.

20. Guadamillas MC, Cerezo A and Del Pozo MA: Overcoming anoikis-pathways to anchorage-independent growth in cancer. J Cell Sci 124: 3189-3197, 2011.

21. Okabe H, Ishimoto T, Mima K, Nakagawa S, Hayashi $H$, Kuroki H, Imai K, Nitta H, Saito S, Hashimoto D, et al: CD44s signals the acquisition of the mesenchymal phenotype required for anchorage-independent cell survival in hepatocellular carcinoma. Br J Cancer 110: 958-966, 2014.

22. Marshall J: Transwell $\left({ }^{\circledR}\right)$ invasion assays. Methods Mol Biol 769: 97-110, 2011.

23. Tapia O, Riquelme I, Leal P, Sandoval A, Aedo S, Weber H, Letelier P, Bellolio E, Villaseca M, Garcia P and Roa JC: The $\mathrm{Pi} 3 \mathrm{~K} / \mathrm{AKT} / \mathrm{mTOR}$ pathway is activated in gastric cancer with potential prognostic and predictive significance. Virchows Arch 465: 25-33, 2014.

24. Sukawa Y, Yamamoto H, Nosho K, Ito M, Igarashi H, Naito T, Mitsuhashi K, Matsunaga Y, Takahashi T, Mikami M, et al: HER2 expression and Pi3K-Akt pathway alterations in gastric cancer. Digestion 89: 12-17, 2014.

25. Xie X, Tang B, Zhou J, Gao Q and Zhang P: Inhibition of the $\mathrm{Pi} 3 \mathrm{~K} / \mathrm{Akt}$ pathway increases the chemosensitivity of gastric cancer to vincristine. Oncol Rep 30: 773-782, 2013.

26. Ye B, Jiang LL, Xu HT, Zhou DW and Li ZS: Expression of $\mathrm{Pi} 3 \mathrm{~K} / \mathrm{AKT}$ pathway in gastric cancer and its blockade suppresses tumor growth and metastasis. Int J Immunopathol Pharmacol 25: $627-636,2012$. 